\title{
Substrate effects on Structural and Optical Properties of ZnO Thin Films Deposited by Chemical Spray Pyrolysis
}

\author{
Abdulazeez O. Mousa ${ }^{1}$, Nadir F. Habubi ${ }^{2}$, Noor A. Nema ${ }^{1}$ \\ ${ }^{1}$ Department of Physics, College of Science, University of Babylon, P.O. Box 4, Babylon, Iraq \\ ${ }^{2}$ Physics Department,Facullty of Education, University of Al- Mustansiriyah, Baghdad, Iraq \\ E-mail address: ${ }^{1}$ Azizliquid_2005@yahoo.com ${ }^{2}$ nadirfadhil@uomustansiriyah.edu.iq \\ 1noor.amir@yahoo.com.
}

Keywords: ZnO thin film; Chemical Spray Pyrolysis; X-ray diffraction; photoluminescence (PL)

\begin{abstract}
ZnO}$ thin films deposited on various substrates including glass, quartz, and ITO (Indium Tin Oxide) coated on glass substrates have been conducted by (CSP) technique. Characterization techniques of X-ray diffraction (XRD), atomic force microscopy (AFM), UVvisible, and photoluminescence (PL) spectra measurements were performed to investigate the effects of substrate on the structural and optical properties of $\mathrm{ZnO}$ thin films. Samples were prepared the thickness of thin films are $(80 \mathrm{~nm})$ and substrate temperature kept at $\left(400^{\circ} \mathrm{C}\right)$ in all cases. Compressed nitrogen was used as a carrier gas. The XRD results indicated that the synthesized $\mathrm{ZnO}$ thin films have a pure wurtzite (hexagonal phase) structure. It can be seen that the highest texture coefficient was in (002) plane. So when a good crystalline substrate like quartz is used for depositing the film, the lattice matching with the deposited film material would be better. AFM measurement showed the grain size ranging from (62-86) $\mathrm{nm}$. The optical studies showed that the thin film for ITO coated glass substrate higher transmittance than glass and quartz substrate. The optical band gap for $\mathrm{ZnO}$ thin films have two values for the same sample, and we will note the band gap of the thin films increasing with increase the crystalline of substrate. The energy gap from photoluminescence (PL) spectra is $(3.369 \mathrm{eV})$ for all samples.
\end{abstract}

\section{INTRODUCTION}

Great unremtiting efforts have been made by the researches to synthesized $\mathrm{ZnO}$ thin films and nanosrtucture $\mathrm{ZnO}$ thin films [1-6]Zinc oxide $(\mathrm{ZnO})$ is a wide band gap direct semiconductor having a band gap of (3.37) $\mathrm{eV}$ at room temperature. It also possesses large exciton-binding energy of $60 \mathrm{meV}$. $\mathrm{ZnO}$ is an attractive semiconductor due to its low cost, nontoxicity, high stability and high transparency in the visible wavelength. It is a promising material for many applications in toxic gas sensors[7], solar cell windows[8], blue and ultraviolet (UV) light emitting devices[9], transparent conductors[10], surface acoustic devices[11], photovoltaic devices[12]. The substrate is very important for the growth of thin films.

In terms of the lattice and thermal mismatching between it and the film because it commonly leads to the development of stress in the deposited film. The properties of semiconducting films ,though primarily determined by the material of the film; however, their physical properties are greatly affected by the technique of film deposition, and also the compatibility with the lattice parameters of the substrate. The material and orientation of the substrate material have a characteristic effect on the nucleation and growth dominated microstructure of a thin film and thereby on its physical properties. Deposition of single crystalline, polycrystalline of amorphous thin films depends on the growth conditions and the substrate. While depositing the film the mismatch between the lattices of the substrate and of the deposited material play a vital role in the properties of the deposited film, especially near the contact interface. For thick films the lattice mismatch tapers out and the material exhibits the bulk properties, although crystallinity of the deposited film may not be good. For very thin films the properties would be essentially dominated by the lattice mismatch at the interface $[13,14]$. In this paper, three materials, glass, quartz and ITO coated glass as a substrate has been studied. To grow high crystalline quality $\mathrm{ZnO}$ 
thin films in large area is much important for material science as well as for device application. So we focus in our work on the effect of these substrates on the structural and optical properties of $\mathrm{ZnO}$ thin films.

\section{EXPERIMENTAL}

Zinc Oxide films have been prepared by chemical spray pyrolysis (CSP) technique onto highly cleaned glass, quartz, and ITO coated glass substrates. A homogeneous solution of $(0.1 \mathrm{M})$ was prepared by dissolving zinc acetate compound $\left(\mathrm{Zn}\left(\mathrm{CH}_{3} \mathrm{COO}\right)_{2} .2 \mathrm{H}_{2} \mathrm{O}\right)$ by re-distilled water and a few drops of glacial acetic acid were then added to stabilize the solution. The solution was stirred for $(30 \mathrm{~min})$ with a magnetic stirrer. We kept the substrate temperature constant at $400^{\circ} \mathrm{C}$ during the preparation of all the samples. The carrier gas was (compressed nitrogen) and the solution is fed into a sprayer nozzle at a pre-adjusted constant atomization pressure (4bar). The crystal structure of the $\mathrm{ZnO}$ thin film was determined by X-ray diffraction (XRD) using Shimadzu (6000) diffractometer with $\mathrm{CuK} \alpha \mathrm{X}$-ray source. Their surface morphology was studied with an atomic force microscope(AFM). The thickness of thin films was measured using (LIMF-10 optical thin film measurement). The optical transmission and reflection spectra are used to study the optical properties of deposit thin films and have been analyzed using UVVIS spectrophotometer at room temperature. The optical energy gap was determined by photoluminescence (PL) spectra using the spectrofluorometer (Lambda 45, Perkin Elmer, Waltham, MA, USA).

\section{RESULTS AND DISCUSSION}

\subsection{Structural Properties}

XRD patterns of the grown $\mathrm{ZnO}$ samples are shown in Figure(1) the deposited

$\mathrm{ZnO}$ films on: (a) glass (b) quartz, and (c) ITO coated glass substrate. Three prominent diffraction peaks concerning (100), (002), and (101) planes for the wurtzite structured $\mathrm{ZnO}$ phase has been observed. Therefore, it can be concluded that all the films deposited in these experimental conditions show highly preferred c-axis (002) orientation growth. In addition to this, ITO peak also emerged in the pattern of $\mathrm{ZnO}$ thin film deposited on ITO coated glass substrate.

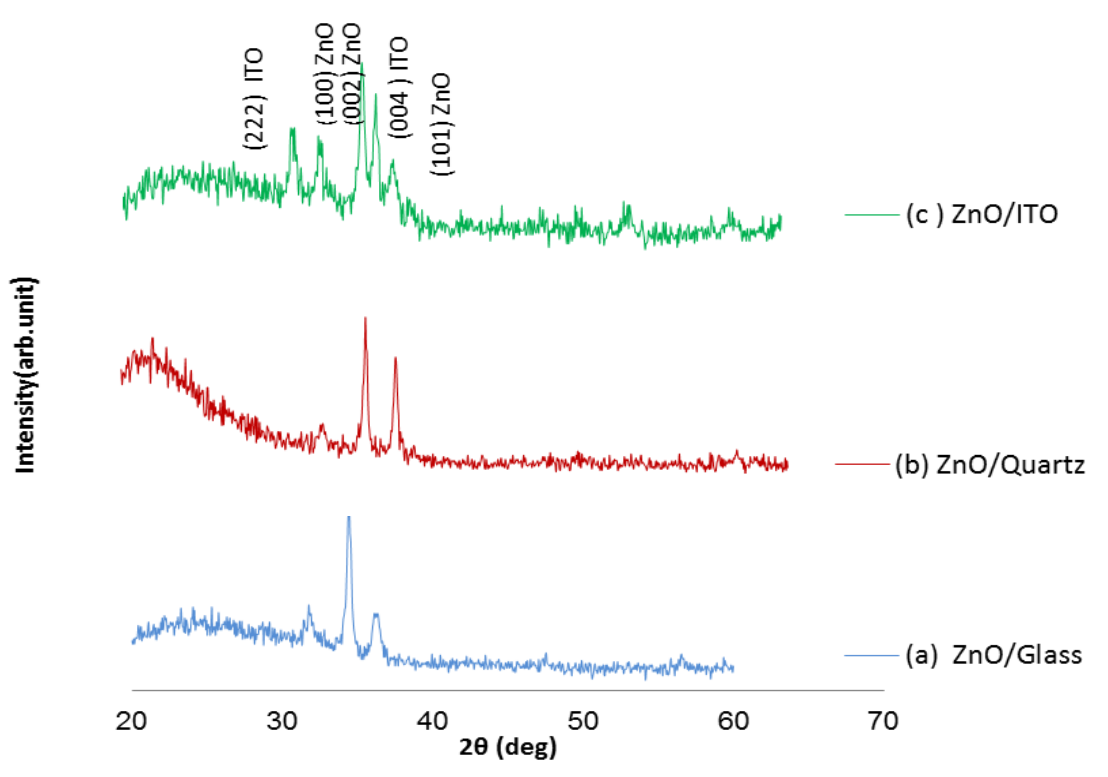

Figure 1: Patterns of ZnO thin films on (a) glass substrate (b) quartz substrate and (c) ITO coated glass substrate. 
It is seen that a lattice mismatch between the substrate and the deposited material plays an important role in the properties of the deposited thin films, especially near the contact interface. This can be seen from the XRD's of ZnO thin films deposited on glass, quartz and ITO coated glass substrates, respectively as shown in the Figure (1). In the case of glass, the concept of lattice parameters as envisaged from the crysallinity point of view for crystalline substrates is almost missing, therefore the deposited film would have its lattice parameters grossly distorted because of the lattice mismatch and its properties would deviate appreciably from the bulk properties of $\mathrm{ZnO}$ is in good agreement with previous results [15]. When a good crystalline substrate like quartz is used for depositing the film, lattice matching with the deposited film material would be better and more uniform laterally along the surface and such a film exhibit properties which would be nearer to the bulk properties of the deposited material. For ITO coated glass the crystallinity of tin oxide though not perfect, is still better than that of uncoated glass therefore the vapors getting deposited on the ITO coated substrate would find a better lattice for getting deposited and hence the lattice mismatch will be not only will be lesser but would extend up to a lesser thickness of the film. The average crystallite size (GS) of the films was determined by the Debye-Scherrer formula [16,17] (the peak widths of the strong diffraction planes have been taken from calculation using the equation following equation and their values were listed in Table $1)$.

$$
G_{S}=\frac{0.94 \lambda}{\beta \cos \theta}
$$

Where $(\beta)$ is the full width at half maximum of characteristic spectrum in units of radians. For the $(002)$ plane, the calculated values of the strain value $(\eta)$, the dislocation density $(\delta)$ and number of crystallites per unit area $(\mathrm{N})$ can be evaluated by using the following relations [18].

$$
\eta=\frac{\beta \cos \theta}{4}
$$$$
\text { (2) } \quad \delta=\frac{1}{G_{s}^{2}}
$$$$
N=\frac{t}{G_{s}}
$$

Where $(\mathrm{t})$ is the thickness for all cases $(80 \mathrm{~nm})$. The calculated average crystallite sizes, the strain, dislocation density, and number of crystallites per unit area, for the $\mathrm{ZnO}$ thin films deposited at different substrate are shown in Table (1).

Table 1: Different structural parameters of $\mathrm{ZnO}$ thin films deposited on glass and quartz, and the

\begin{tabular}{|c|c|c|c|c|c|c|c|c|}
\hline $\begin{array}{c}\text { Thin films } \\
\text { sample }\end{array}$ & $\begin{array}{l}2 \theta \\
(\mathrm{deg})\end{array}$ & $\begin{array}{l}\text { (hkl) } \\
\text { plan }\end{array}$ & $\begin{array}{c}\mathbf{d}(\AA) \\
\text { observed }\end{array}$ & $\begin{array}{c}\text { FWHM } \\
\text { (deg) }\end{array}$ & $\begin{array}{c}\text { GS(XRD) } \\
(\mathrm{nm})\end{array}$ & $\begin{array}{l}\mathbf{8 X 1 0 ^ { \wedge } 1 4} \\
\left(\operatorname{lin} \mathrm{m}^{-2}\right)\end{array}$ & $\begin{array}{c}\eta X 10^{\wedge}-4 \\
\left(\operatorname{lin}^{-2} m^{-4}\right)\end{array}$ & $\mathbf{N}$ \\
\hline ZnO/glass & 34.44 & $(002)$ & 2.601 & 0.3472 & 25.021 & 15.972 & 14.469 & 3.197 \\
\hline $\mathrm{ZnO} /$ quartz & 34.664 & $(002)$ & 2.585 & 0.423 & 20.54 & 23.702 & 17.625 & 3.894 \\
\hline \begin{tabular}{|l|}
$\mathrm{ZnO} / \mathrm{ITO}$ \\
coated glass
\end{tabular} & 34.689 & $(002)$ & 2.583 & 0.402 & 21.603 & 21.426 & 16.758 & 3.703 \\
\hline
\end{tabular}
ITO coated glass substrates.

Table (1) shows the average crystallite sizes of the as grown films on glass, quartz, and the ITO coated glass substrate was found to be decreasing with the increasing of crystalline substrates. The results revealed that the strain and dislocation density increase with the increasing of the crystalline substrate. Figure (2) shows AFM topographies of the $\mathrm{ZnO}$ thin films deposited on glass, quartz, and the ITO coated glass Substrate. The calculated values of roughness average and the grain sizes are summarized in Table (2). It has been observed that a minimum surface 
roughness has been found for the $\mathrm{ZnO}$ on quartz $(0.632 \mathrm{~nm})$ while the $\mathrm{ZnO} / \mathrm{ITO}$ coated glass has the maximum value $(3.17 \mathrm{~nm})$. The smallest grain size was found for $\mathrm{ZnO}$ on glass and $(76 \mathrm{~nm})$ and largest for the $\mathrm{ZnO}$ on quartz $(99 \mathrm{~nm})$. It is known that the increase in surface roughness may cause deterioration of the electrical and optical properties [19]. These results, together with the $\mathrm{XRD}$ analysis, clearly indicate that the crystallinity is influenced by the nature of substrates. This is in good agreement with other results [20].

Table 2: AFM topographies of the ZnO thin films deposited on glass, quartz, and the ITO coated glass Substrate.

\begin{tabular}{|c|c|c|c|}
\hline Thin films sample & $\begin{array}{c}\mathbf{G}_{\mathbf{s}} \\
(\mathbf{n m})\end{array}$ & $\begin{array}{c}\text { Roughness averge } \\
(\mathbf{n m})\end{array}$ & $\begin{array}{c}\text { Root mean Square } \\
(\mathbf{n m})\end{array}$ \\
\hline ZnO/glass & 76 & 0.723 & 0.929 \\
\hline \hline ZnO/quartz & 99 & 0.632 & 0.815 \\
\hline \hline $\begin{array}{c}\text { ZnO/ITO coated } \\
\text { glass }\end{array}$ & 96.49 & 3.17 & 3.72 \\
\hline
\end{tabular}

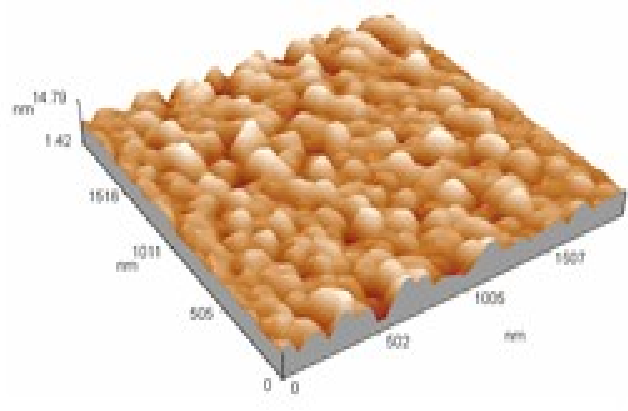

(a)
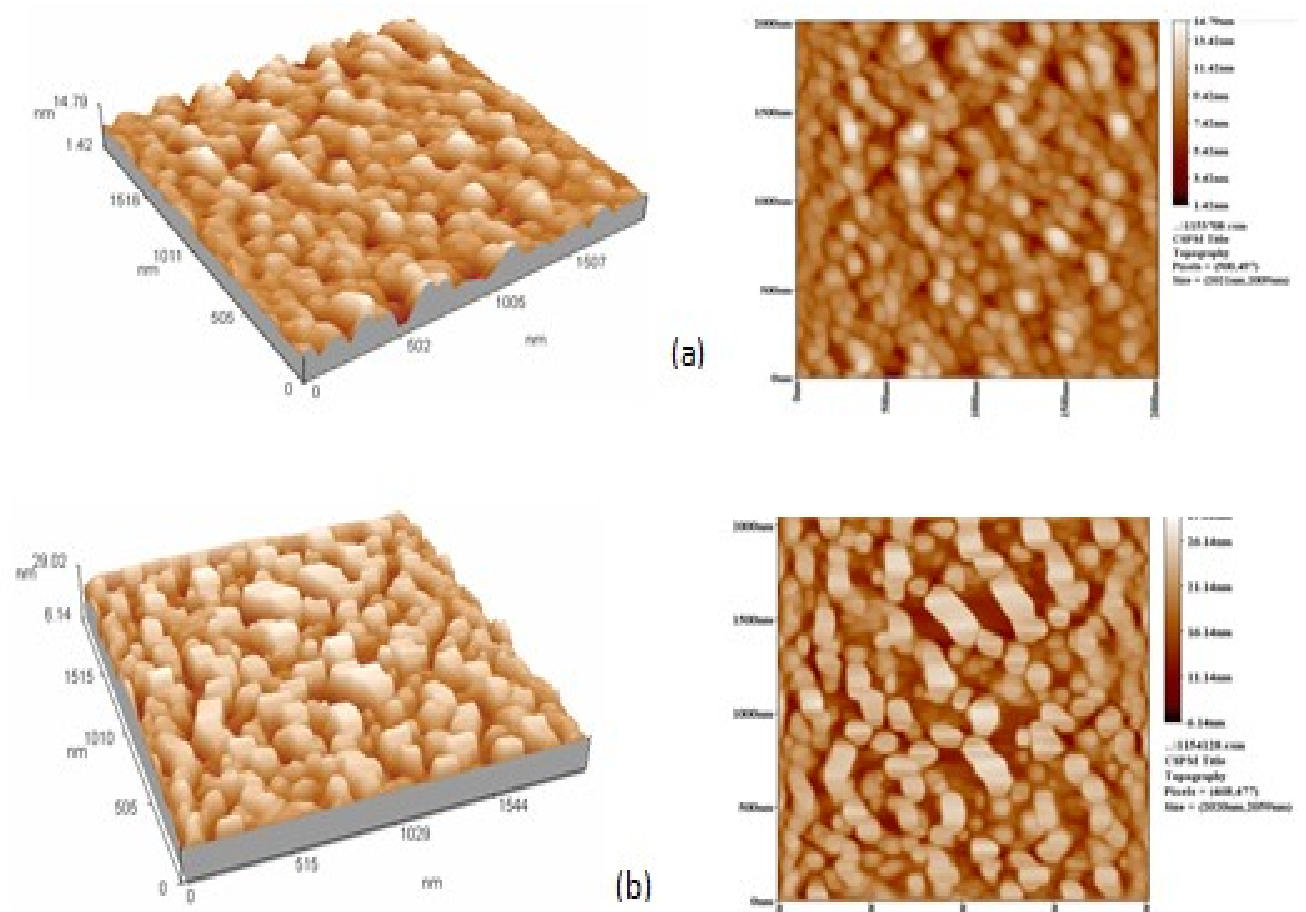

(b)
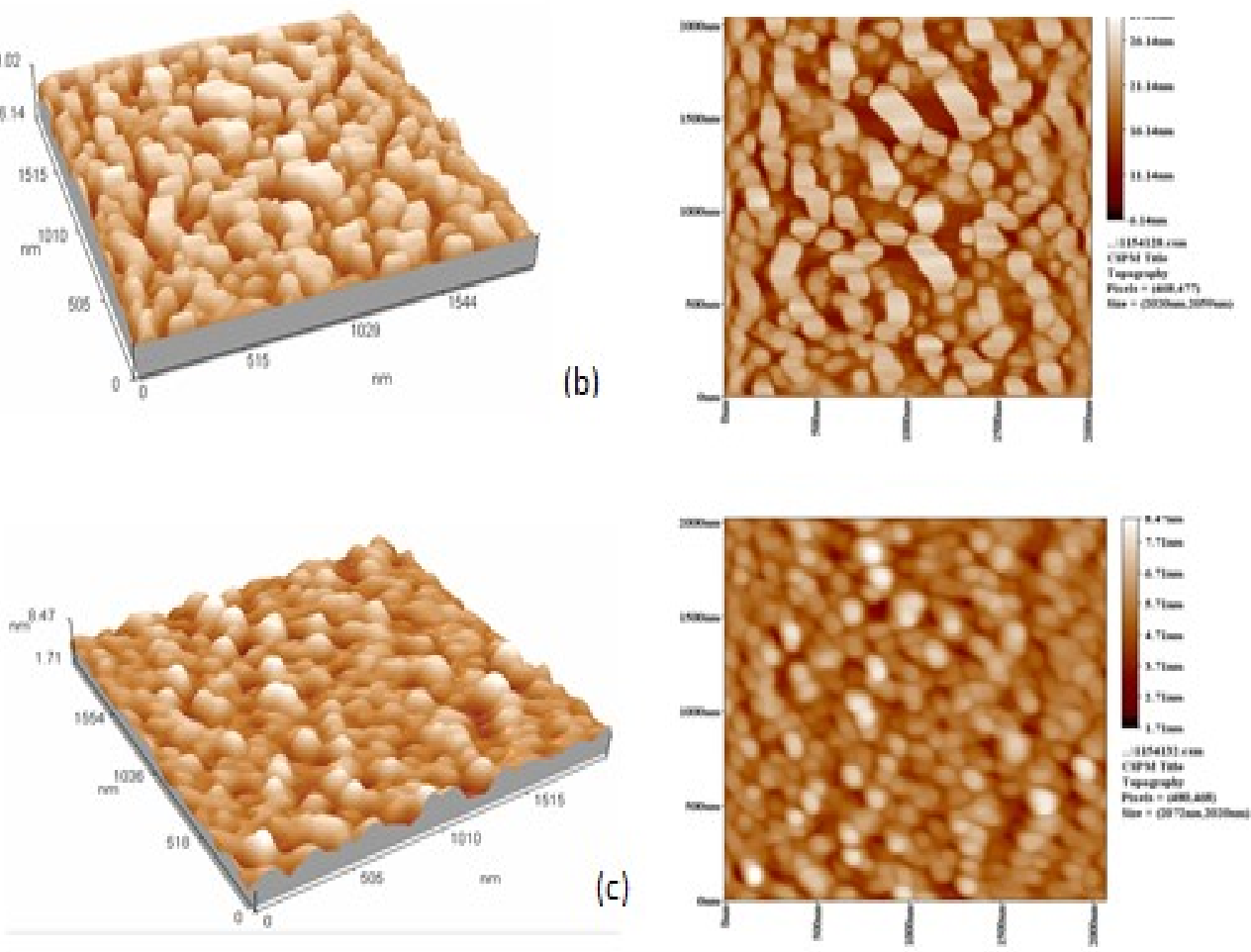

Figure 2: AFM images of $\mathrm{ZnO}$ thin films deposited on glass(a), quartz (b), and the ITO coated glass (c) substrates. 


\subsection{Optical Properties}

UV-VIS Spectrophotometer was used to measure the transmittance and absorption of $\mathrm{ZnO}$ film deposited at different conditions within the wavelength range $(300-800 \mathrm{~nm})$. The background correction was taken for each scan. The transmittance and reflectance data can be used to calculate absorption coefficients $(\alpha)$ of the films atdifferent wavelength. which were used to determine the band gap, $\mathrm{Eg}$, using the relation[21].

$$
\alpha h v=A\left(h v-E_{g}\right)^{1 / 2}
$$

Where $A$ is a constant, Figure (3) shows the transmission spectra of $\mathrm{ZnO}$ thin films deposited on glass, quartz, and ITO coated glass substrates. The films deposited on the quartz substrate show high transmission compared to the films deposited either on the glass or on the ITO coated glass substrate. By comparison, the absorption edge is observed at a slightly lower wavelength range for the quartz substrate. The shift of absorption edge may be attributed to the difference in grain size [22] and or carrier concentration. From the results of XRD the $\mathrm{ZnO}$ /quartz thin film relatively small grain size; this was probably why the blue shift occurred. It suggested that the grain size indeed affects the optical properties significantly. In all cases, the films were found to be highly transmittance in the visible wavelength region with an average transmittance $80 \%$, this is in agreement with [23] Figure (4) Plotting $(\alpha h v)^{2}$ as a function of photon energy (hv)and extrapolating the linear portion of the curve to absorption equal to zero gives the value of the direct band gap. The optical band gap energies determined from the obtained spectra are (3.2 and 3.38), (3.29 and 3.46), and(3.22 and 3.41) eV for $\mathrm{ZnO}$ thin films deposited on glass, quartz and ITO coated glass substrates respectively. While it is slightly higher than that $(3.37 \mathrm{eV})$ previously reported. The higher value of the band gap on quartz substrate may be due to smaller crystallite size. The above two values of the same sample may be related to the formation of nanostructures of $\mathrm{ZnO}$ on the bulk of the remaining $\mathrm{ZnO}$ thin film. Another explaining for the appearance of two values of energy may be referring to the formation of defect states in our prepared sample.

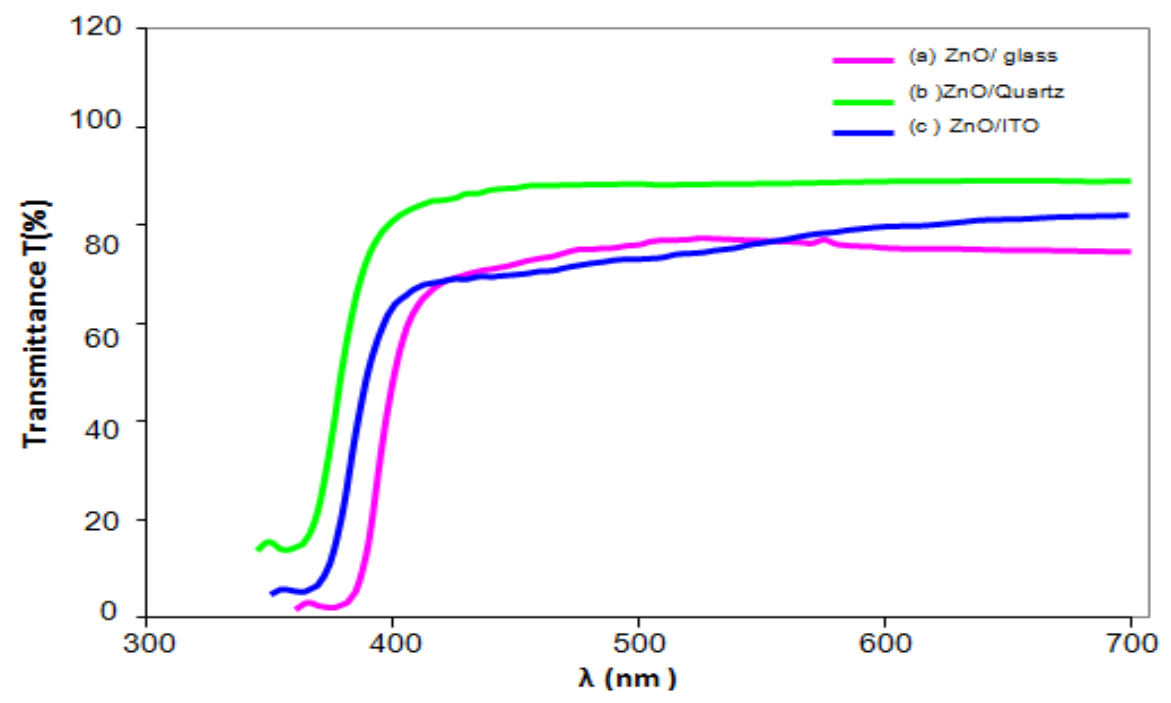

Figure 3: UV-Visible spectrum of ZnO films deposited on (a)glass, (b)quartz and (c)ITO coated glass. 

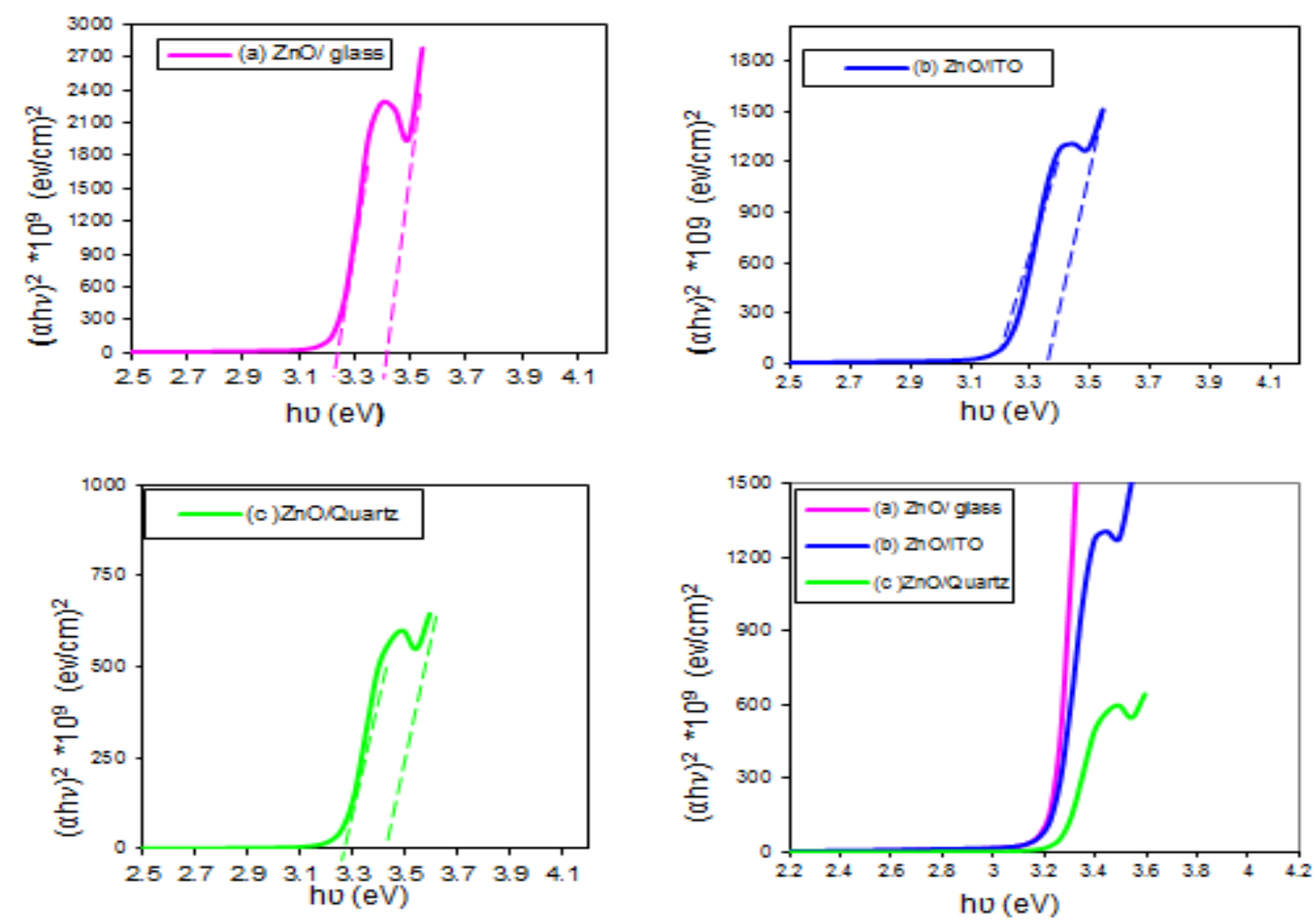

Figure 4: $(\alpha h v)^{2}$ vs. (hv) plot of ZnO films deposited at different substrate (a)glass, (b) ITO coated glass, (c) quartz, and (d) comparison between them.

Table (3) Shows that the absorption coefficient $(\alpha)$ extinction coefficient, refractive index $\mathrm{n}$, real dielectric constant $\left(\varepsilon_{\text {Real }}\right)$, and imaginary dielectric constant $\left(\varepsilon_{\mathrm{Im}}\right)$ for $\mathrm{ZnO}$ deposition on glass, quartz, and ITO coated on glass substrate. From the table, it is clear that a minimum refractive index (n) has been found for the $\mathrm{ZnO}$ deposited on ITO coated glass substrates, while the $\mathrm{ZnO}$ on quartz has the maximum. The the smallest grain size was found for $\mathrm{ZnO}$ on glass and (76 $\mathrm{nm}$ ) and largest for the $\mathrm{ZnO}$ respectively. These results are in conformity with the results calculated from Sellmeir's equation [24]. The smallest absorption coefficient was found for $\mathrm{ZnO}$ in quartz and largest for the $\mathrm{ZnO}$ in ITO coated glass substrates. The decreased absorption coefficient will also reflect in lower value of $\mathrm{n}$ as it is also evident from the mathematical expressions for $\mathrm{n}$ and $\mathrm{k}$ as given in Table (3).

Table 3: Optical constant at $\lambda \approx 390 \mathrm{~nm}$ of $\mathrm{ZnO}$ films deposition on glass, quartz, and ITO coated on glass substrate

\begin{tabular}{|c|c|c|c|c|c|}
\hline substrate & $\begin{array}{c}\text { Absorption } \\
\text { Coefficient } \\
\alpha * 10^{4}\left(\mathrm{~cm}^{-1}\right)\end{array}$ & $\begin{array}{l}\text { Extenction } \\
\text { Coefficient } \\
\text { (K) }\end{array}$ & $\begin{array}{l}\text { Refractive } \\
\text { Index (n) }\end{array}$ & $\begin{array}{c}\text { Real } \\
\text { Dielectric } \\
\text { Constant } \\
\left(\varepsilon_{\text {Real }}\right)\end{array}$ & $\begin{array}{c}\text { Imaginary Dielectric } \\
\text { Constant }\left(\varepsilon_{\text {Im. }}\right)\end{array}$ \\
\hline $\mathrm{ZnO} /$ glass & 0.2305 & 0.1941 & 1.941 & 3.68 & 0.748 \\
\hline ZnO/Quartz & 0.135 & 0.1091 & 2.048 & 3.179 & 0.439 \\
\hline $\mathrm{ZnO} / \mathrm{ITO}$ & 0.2328 & 0.1938 & 1.5441 & 2.345 & 0.598 \\
\hline
\end{tabular}

Photoluminescence (PL) studies provide information about different energy states available between valence and conduction bands responsible for irradiative recombination. Room temperature $\mathrm{PL}$ in $\mathrm{ZnO}$ attributed to the recombination and emission of free excitons through an exciton -exciton collision process, where one of the exciton radioactively recombines to generate 
photon [25]. Figure (5) shows the Photoluminescence spectra obtained from the $\mathrm{ZnO}$ thin films deposited on glass, quartz, and ITO coated glass substrate and comparison between them (a, b, c, and d) respectively.
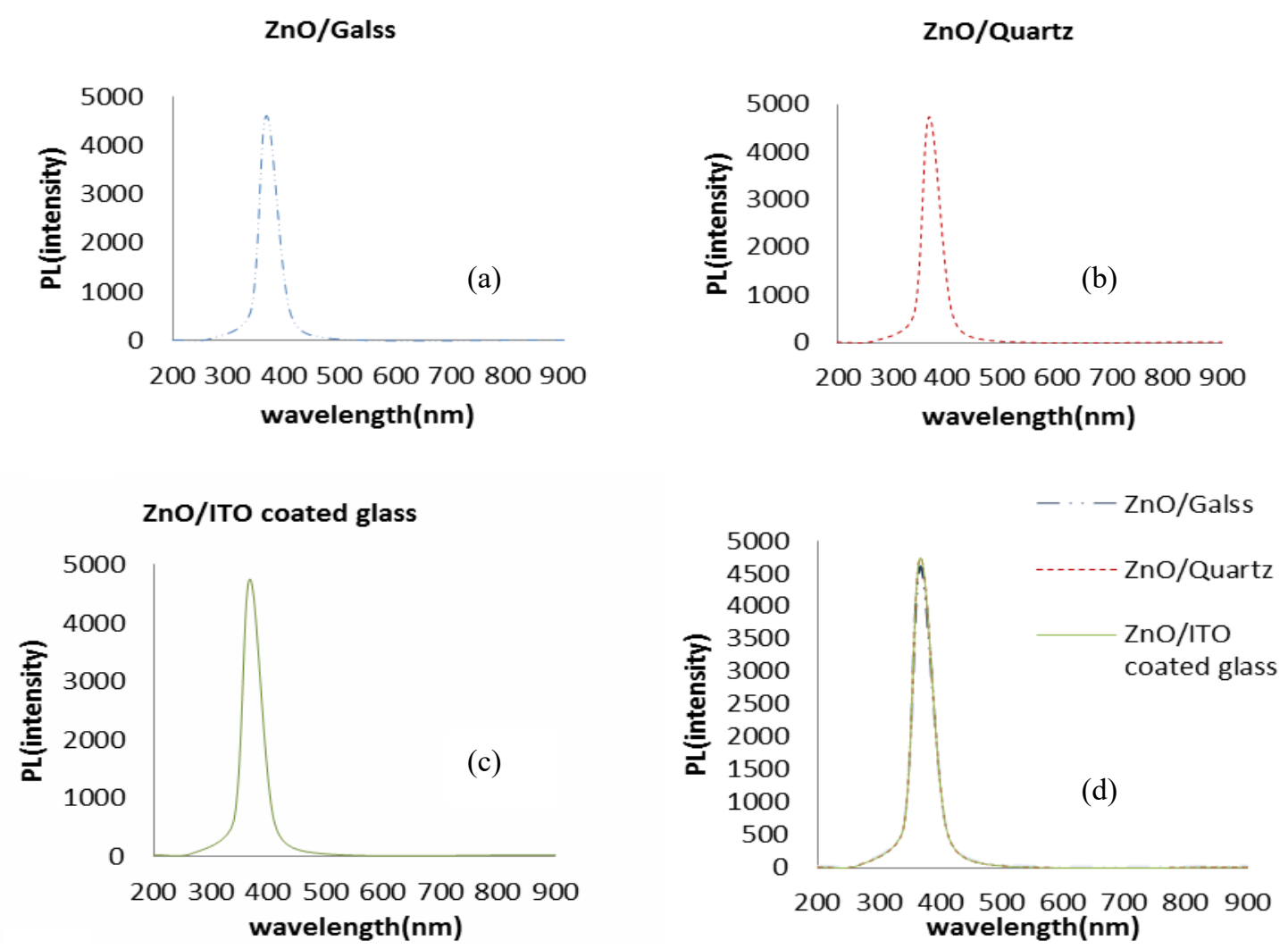

Figure 5: Photoluminescence spectra obtained from the $\mathrm{ZnO}$ thin films deposited on glass, (b) quartz, (c)ITO coated glass substrate, and (d) comparison between them.

It is interesting to note that the $\mathrm{ZnO}$ film deposited at different substrate glass, quartz, and ITO coated glass observed only strong ultraviolet emission at $368 \mathrm{~nm}(3.369 \mathrm{eV})$ [22] the same value for all samples. This emission in the UV region confirms the formation of the highest quality crystal structure of the thin films. However, the single ultraviolet emission in the present experiment is obtained from a nanocrystalline $\mathrm{ZnO}$ thin film. The intensity of $\mathrm{ZnO}$ on glass less than $\mathrm{ZnO}$ on quartz and ITO coated glass. As a result, highest UV emission with no deep-level emission was observed. Therefore, it is deduced that single UV emission should be obtained from the $\mathrm{ZnO}$ film with near perfect stoichiometry.

\section{CONCLUSIONS}

$\mathrm{ZnO}$ thin films was obtained by (CSP) deposition on glass, quartz, and ITO coated glass substrate. The different patterns reveal a good crystalline behavior with the hexagonal wurtzite structure for all samples. The better crystallinity for $\mathrm{ZnO}$ thin films deposited on quartz, ITO coated glass, and glass substrate respectively. The results revealed that the strain and dislocation density increase with the increasing of the crystalline substrate. The grain size of the thin films , calculated from AFM in the range of (76-99 $\mathrm{nm})$. Optical transmittance spectra of $\mathrm{ZnO}$ thin films on quartz about $90 \%$ greater than glass and ITO coated glass. The UV-VIS optical studies showed that their optical band gap have two values for the same sample may be related to the formation of nanostructures of $\mathrm{ZnO}$ on the bulk of the remaining $\mathrm{ZnO}$ thin film and the higher 
value of the band gap on quartz substrate may be due to smaller crystallite size. It is interesting to note that the $\mathrm{ZnO}$ film deposited at different substrate glass, quartz, and ITO coated glass observed only strong ultraviolet emission at $368 \mathrm{~nm}(3.369 \mathrm{eV})$ from PL studied. Obviously this would be a very important criterion in the design of thin film devices.

\section{References}

[1] A. A. Yosif,A. J. Haider and N. F. Habubi, Nanoelectronics and materials, 5 (2012)47-55.

[2] A, A. Yousif, N. F. Habubi and A.J. Haider, J. of Nano and Electronic Physcis 4,(2012)020076.

[3] S. S. Chiad, A. M. Eyada Ibrahim and N.F. Habubi ,Tikrit J. of Pure Science ,17 (2012) 156159.

[4] N. F. Habubi, S. S. Chiad,S. F. Oboudi and Z. A. Toma,International Letters of Chemistry, Physics and Astronomy,4(2013)1-8

[5] R. A. Ismail, N. F. Habubi, H. R. Abid, International Letters of Chemistry , Physics and Astronomy,4(2014)37-47

[6] N. F. Habubi , R. A. Ismail, H. R. Abid, Surface Review and Letters, 22 (2015)1550027-8

[7] A.P. Mitra and H.S. Chatterjee Maiti, Mater. Lett. 35 (1998) 33-38.

[8] W.J. Jeong, S.K. Kim, and G.C. Park, Thin Solid Films 180 (2006) 506.

[9] D.M. Bagall, Y.F. Chen, Z. Zhu, T. Yao, S. Koyama, M.Y. Shen, and T. Goto, Appl. Phys. Lett., 70 (1997) 2230.

[10] V. Srikant, S. Valter, and R. David, "Effect of substrate orientation", J. Am. Ceram. Soc., 78 (1995)1931.

[11] Amlouk, F. Touhari, S. Belgacem, N. Kamoun, D. Barjon, and R. Bennaceur, Phys. Stat. Sol. (A), 163 (1997) 73-80.

[12] T. Pauporte and D. Lincot,electrochim. Acta, 45(2000)3345.

[13] R. Eason, "pulsed laser deposition of thin films applications-led growth of functional materials", John Wiley \& Sons, (2007).

[14] T. Makino, C. H. Chia, N.T. Tuan, Y. Segawa, M. Kawasaki, A. Ohotomo, K. Tamura and H.Koinuma. Appl. Physi. Lett. 76 (2000) 3549.

[15] S. Lemlikchia, S. Abdelli-Messaci, S. Lafane, T. Kerdja, A. Guittoum and M. Saad, "Study of structural and opti cal properties of $\mathrm{ZnO}$ films grown by pulsed laser deposition" , Applied Surface Science, 256 (2010) 5650-5655.

[16] S.T. Rattanachan, P. Krongarrom, and T. Fangsuwannarak, American Journal of Applied Sciences 10 (2013) 1427-1438.

[17] A. H. Moharram, S. A. Mansour, M. A. Hussein, and M. Rashad, Journal of Nanomaterials 2014 (2014) 716210-5

[18] A. Singh and P. Kumar, International Nano Letters 3 (57) ( 2013)1-6

[19] B. D. Ngom, T. Mpahane, N. Manyala, O. Nemraoui, U. Buttner, J. B. Kana, A. Y. Fasasi, M. Maaza, and A. C. Beye, Applied Surface Science, 255(2009) 4153-4158.

[20] C. Li, M. Furuta, T. Matsuda, T. Hiramatsu, H. Furuta and T. Hirao, Thin Solid Films, 517( 2009). 3265-3268.

[21] P. Singh, A. Koushal, and D. Kaur, J. Alloy Compound, 471(2009) 11-15.

[22] L. Zhao, J. Lian, Y. Liu, and Q. Jian,”, Appl. Sur. Sci., 252(2006) 8451. 
[23] E. S. Tüzemen, S. Eker, H. Kavak, and R. Esen, Appl. Surf. Sci.,255 (2009)6195-6200..

[24] N. Bouchenak Khelladi, and N.E. Chabane Sari,American Journal of Optics and Photonics 1 (2013)1-5.

[25] K. Dhananjaya, "Property modulation of Zinc Oxide through doping", PhD thesis Indian Institute of Science, Bangalore (2007). 